TITLE:

\title{
Near-source released energy in relation to fracture energy on earthquake faults
}

\author{
AUTHOR(S): \\ Mikumo, Takeshi; Fukuyama, Eiichi
}

\section{CITATION:}

Mikumo, Takeshi ... [et al]. Near-source released energy in relation to fracture energy on earthquake faults. Bulletin of the Seismological Society of America 2006, 96(3): 1177-1181

\section{ISSUE DATE:}

2006-06

URL:

http://hdl.handle.net/2433/193416

RIGHT:

(C) 2006 Bulletin of the Seismological Society of America 


\title{
Near-Source Released Energy in Relation to Fracture Energy on Earthquake Faults
}

\author{
by Takeshi Mikumo and Eiichi Fukuyama
}

\begin{abstract}
The near-source energy released on a fault is estimated through the strain energy change and the fracture energy from the results of kinematic waveform inversion and dynamic modeling for two different types of earthquakes: a shallow crustal earthquake, the 2000 Tottori, Japan $\left(M_{\mathrm{w}} 6.6\right)$ earthquake, and an in-slab event, the 1999 Oaxaca, Mexico $\left(M_{\mathrm{w}} 7.5\right)$ earthquake. The procedure incorporates the spatial distribution of slip, critical slip-weakening distance, stress drop, and strength excess. The results show that the near-source energy density estimated over major asperities on the fault is nearly the same for the two earthquakes, while the fracture energy on the in-slab fault is appreciably larger than that for the crustal fault, suggesting higher strength in the in-slab fault zone. The near-source released energy on major asperities is significantly larger than the fracture energy in the two earthquakes.
\end{abstract}

\section{Introduction}

The seismic energy radiated from an earthquake source may be one of the fundamental parameters for understanding the overall features of dynamic rupture on the fault. To estimate the radiated seismic energy, numerous studies have been made to date, based not only on teleseismic waves by integrating outgoing energy flux with correcting for path attenuation effects and site response, but also on regional data without these effects (e.g., Kanamori et al., 1993; Singh and Ordaz, 1994; Choy and Boatwright, 1995; McGarr, 1999; Kanamori and Heaton, 2000; Ide and Beroza, 2001; Ide, 2002; Favreau and Archuleta, 2003; Abercrombie and Rice, 2004).

On the other hand, recent kinematic waveform inversion and dynamic modeling of the rupture process enabled us to estimate the slip and stress change distributed on the fault for a number of large- to moderate-size earthquakes. It is now possible to get a direct estimate of released energy on the fault by incorporating all the above information. In the present article, we estimate the near-source released energy based on its new definition (Fukuyama, 2005) with respect to the fracture energy under a dynamic slip-weakening model for two different types of earthquakes.

\section{Energy Balance on the Fault under a Simple Slip-Weakening Model}

Recently, Fukuyama (2005) proposed a new definition for near-source released energy, which is different from the traditional seismic radiation energy evaluated at sufficiently long distances away from the source. This new concept is for the energy released close to the fault surface, which can be derived from the energy balance equation of Kostrov (1974) and Kostrov and Das (1988). This is explicitly given in equation (11) in Fukuyama (2005),

$E_{\mathrm{q}}^{\prime}=\int_{\Sigma}\left[\left(\sigma_{i j}^{0}-\sigma_{i j}^{1}\right) a_{i}^{1} n_{j}+\int_{t_{0}}^{t_{\mathrm{m}}}\left(d \sigma_{i j} / d t\right) a_{i} n_{j} d t\right] d S$

where $\sigma_{i j}$ is the stress component, $d \sigma_{i j} / d t$ is its time derivative, $a_{i}=u_{i}^{+}-u_{i}^{-}$is the dislocation between the upper and lower fault surfaces, and $n_{j}$ is a unit vector normal to the surface. The surface integral is taken close to cover the upper and lower fault surfaces $\Sigma$, and time $t_{\mathrm{m}}$ should be taken to cover the termination of fault rupture process. Superscripts 0 and 1 stand for the values at $t=0$ and $t_{\mathrm{m}}$, respectively. Note that $t=t_{0}$ and $t=t_{\mathrm{m}}$ have different values for each point on the fault, in other words, they may be written as $t_{0}(\xi)$ and $t_{\mathrm{m}}(\xi)$, where $\xi$ is the coordinate on the fault.

Now we consider a heterogeneous fault surface, where the slip distribution has been estimated on the fault surface from kinematic waveform inversion, and the distribution of the resultant dynamic and static stress changes and the strength excess have been calculated from dynamic modeling. We assume here a simple slip-weakening constitutive relation (Andrews, 1976a,b) for dynamic rupture on each subfault, in which the initial stress $\sigma_{0}$ increases up to the yield stress $\sigma_{\mathrm{y}}$ and then decreases linearly with ongoing slip to the dynamic friction level $\sigma_{\mathrm{f}}$ (Fig. 1). The slip at this point is the critical slip-weakening distance $D_{\mathrm{c}}$, and the final slip is $D\left(=a_{i}^{1}\right) . \sigma_{i j}^{0}$ and $\sigma_{i j}^{1}$ in the first term of equation (1) can be replaced by $\sigma_{0}$ and $\sigma_{\mathrm{f}}$, respectively. Under the above 


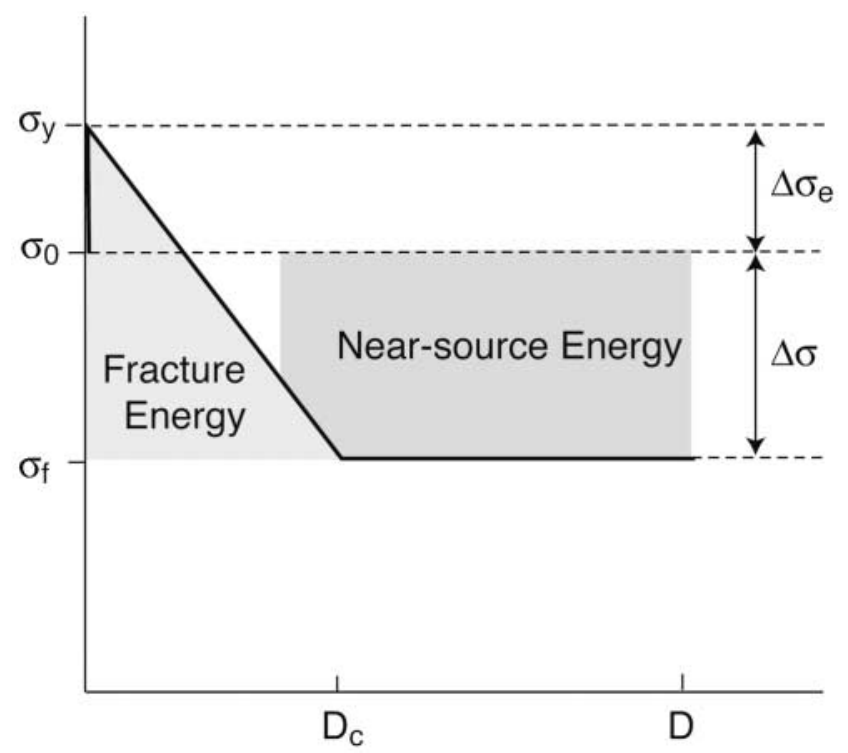

Figure 1. Fracture energy and near-source released energy on a unit area of the fault, under a simple slip-weakening behavior (modified from Andrews, 1976a,b).

linear slip-weakening law, the integration of the timedependent part in the second term becomes

$\int_{t_{0}}^{t_{\mathrm{m}}}\left(d \sigma_{i j} / d t\right) a_{i} n_{j} d t=\int_{\sigma_{\mathrm{y}}}^{\sigma_{\mathrm{f}}} a_{i}\left(\sigma_{i j}\right) n_{j} d \sigma_{i j}=-(1 / 2) D_{\mathrm{c}}\left(\sigma_{\mathrm{y}}-\sigma_{\mathrm{f}}\right)$,

since $a_{i}\left(\sigma_{i j}\right) n_{j}=D_{\mathrm{c}}\left(\sigma_{\mathrm{y}}-\sigma_{i j}\right) /\left(\sigma_{\mathrm{y}}-\sigma_{\mathrm{f}}\right)\left(0<a_{i}<D_{\mathrm{c}}\right)$.

Therefore, equation (1) can be rewritten as

$$
E_{\mathrm{q}}^{\prime}=\int_{\Sigma}\left(\sigma_{0}-\sigma_{\mathrm{f}}\right) D d S-(1 / 2) \int_{\Sigma}\left(\sigma_{y}-\sigma_{\mathrm{f}}\right) D_{\mathrm{c}} d S
$$

The first term in the right-hand side of equation (2) corresponds to twice the strain energy change $\Delta W$ due to slip under stress change on the fault (c.f. Steketee, 1958), while the second term indicates the fracture energy $E_{\mathrm{g}}$. Thus, $E_{\mathrm{q}}^{\prime}=2 \Delta W-E_{\mathrm{g}}$, includes the strain energy due to nearfault deformation and the seismic energy radiated from the fault (Fig. 1). The total near-source released energy can be estimated by performing integration in equation (2). $E_{\mathrm{q}}^{\prime}$ and $E_{\mathrm{g}}$ appearing in equation (2) may be rewritten in the following form:

$$
\begin{gathered}
E_{\mathrm{q}}^{\prime}=\sum E_{\mathrm{q}_{j}}^{\prime}, \text { and } E_{\mathrm{g}}=\sum E_{\mathrm{g}_{j}} \\
E_{\mathrm{q}_{j}}^{\prime}=(1 / 2) \Delta \sigma_{j} D_{j}\left[2-(1+S) D c_{j} / D_{j}\right] A_{j}, \text { and } \\
E_{g_{j}}=(1 / 2) \Delta \sigma_{b j} D_{c_{j}} A_{j},
\end{gathered}
$$

where $\Delta \sigma=\sigma_{0}-\sigma_{\mathrm{f}}$ is the dynamic stress drop, $\Delta \sigma_{\mathrm{e}}=\sigma_{\mathrm{y}}$ $-\sigma_{0}$ is the strength excess, $\Delta \sigma_{\mathrm{b}}=\sigma_{\mathrm{y}}-\sigma_{\mathrm{f}}$ is the breakdown stress drop, and $S=\Delta \sigma_{\mathrm{e}} / \Delta \sigma=\Delta \sigma_{\mathrm{b}} / \Delta \sigma-1$ is called the stress factor (Das and Aki, 1977). $A_{j}$ is the area of subfault. $E_{\mathrm{q}_{j}}{ }^{\prime}$ and $E_{\mathrm{g}_{j}}$ may be regarded as local energies and can be estimated on major asperities from the final slip $D_{j}$, dynamic stress drop $\Delta \sigma_{j}$, strength excess $\Delta \sigma_{\text {ej }}$, and the slip-weakening distance $D_{\text {cj }}$, using the results from kinematic and dynamic calculations. Here subscript $j$ stands for the index of the subfault. Each of the ratios of the total near-source energy $E_{\mathrm{q}}^{\prime}$, the total fracture energy $E_{\mathrm{g}}$, and seismic moment $M_{0}$, to the strain energy $\Delta W$, can also be evaluated from the above relation.

\section{Estimate of Critical Slip-Weakening Distance}

The critical slip-weakening distance $D_{\mathrm{c}}$ has so far been estimated for several large earthquakes through various techniques (e.g., Ide and Takeo, 1997; see also a review by Mikumo et al., 2003). Recent studies (Mikumo et al., 2003; Mikumo and Yagi, 2003) estimated this dynamic parameter from the time of peak value in the slip-velocity function on each subfault, which has been obtained from kinematic waveform inversion in the frequency range between 0.05 and $0.5 \mathrm{~Hz}$, with corrections through dynamic rupture calculations $(\mathrm{Fu}-$ kuyama et al., 2003). The estimated $D_{\text {c }}$ values, with uncertainties of about $30 \%$, appear to be more or less dependent on local maximum slip $D$, although this apparent dependence might be spurious due to the effects of low-pass filtering of the observed records (Spudich and Guatteri, 2004), the shape of the assumed source time function (Piatanesi et al., 2004; Tinti et al., 2005), or the effects of rupture propagation over large-size subfaults (Yasuda et al., 2005). There is still much debate as to whether such scale dependence is real or if $D_{c}$ is almost constant on a single fault within the accuracy of its estimate. If this type of scale effect is real, it might be expected to come from the roughness of the fault surface, as suggested by laboratory experiments (e.g., Okubo and Dieterich, 1984; Ohnaka and Shen, 1999; Ohnaka, 2003) and by field surveys of natural faults (e.g., Scholz and Aviles, 1986; Power et al., 1987) in which $D_{\text {c }}$ was found to be distributed as a fractal-like structure of the fault roughness and hence is expected to scale with slip. An increase of $D_{\mathrm{c}}$ and the fracture energy with rupture propagating distance keeping such a scaling relation is also suggested by theoretical and numerical calculations (Andrews, 2004; Aochi and Ide, 2004). We will not discuss this problem here.

\section{Near-Source Released Energy and Fracture Energy}

Since the distribution of maximum slip $D$, dynamic stress drop $\Delta \sigma$, and the strength excess $\Delta \sigma_{\mathrm{e}}$ has been estimated for the two earthquakes (Mikumo et al., 2003; Mikumo and Yagi, 2003), the near-source energy and the fracture energy can be estimated incorporating $D_{\mathrm{c}}$ and $D$ through equation (4), although $\Delta \sigma_{\mathrm{e}}$ is somewhat less well resolved than $\Delta \sigma$ and also has some trade-off with $D_{\mathrm{c}}$ in the numerical calculations. In this section, we estimate the fracture energy and near-source energy released on major asperities (high 
slip and large stress-drop zones) on the fault, but not over the entire fault, of the two earthquakes.

Figure 2 shows the distributions of (a) the normalized fracture energy $E_{\mathrm{g}_{j}} / A_{j}$, and (b) the normalized near-source energy $E_{\mathrm{q} j}^{\prime} / A_{j}$, for the case of the Tottori earthquake. Several subfaults with $\Delta \sigma<0$ or $D_{\mathrm{c}}<40 \mathrm{~cm}$ have been excluded due to its poor resolution. In this case, $\Delta \sigma$ ranges between 0.6 and $8.5 \mathrm{MPa}$, while $\Delta \sigma_{\mathrm{e}}$ ranges between 0.5 and $4.5 \mathrm{MPa}$. It can be seen that $E_{\mathrm{g} j} / A_{j}$ ranges between 3 and $5 \mathrm{MJ} / \mathrm{m}^{2}$ on one asperity (in Fig. 8, Mikumo et al., 2003), and that $E_{\mathrm{q}_{j}}{ }^{\prime} /$ $A_{j}$ in this zone is found to be between 8 and $12 \mathrm{MJ} / \mathrm{m}^{2}$. We integrate these energies over 30 major subfaults (each with a dimension of $2 \mathrm{~km} \times 2 \mathrm{~km}$ ) covering this asperity, then we find $E_{\mathrm{g}}=\Sigma E_{\mathrm{g}_{j}}=2.5 \times 10^{8} \mathrm{MJ}, E_{\mathrm{q}}^{\prime}=\Sigma E_{\mathrm{q}_{j}}^{\prime}=5.9 \times$ $10^{8} \mathrm{MJ}$, and $2 \Delta W=8.4 \times 10^{8} \mathrm{MJ}$. Their ratios are $E_{\mathrm{q}}^{\prime} /$ $2 \Delta W=0.70, E_{\mathrm{g}} / 2 \Delta W=0.30$, and $E_{\mathrm{q}}^{\prime} / E_{\mathrm{g}}=2.1$. We also found $E_{\mathrm{q}}^{\prime} / M_{0}=9.0 \times 10^{-5}$ on this asperity. The relation suggests that the near-source energy released on this major asperity of the fault is about $70 \%$ of twice the strain energy and 2.1 times the fracture energy spent to break that part of the fault.

Similar estimates are shown in Figure 3 for the case of the 1999 Oaxaca earthquake, where subfaults with $\Delta \sigma<0$

a) Distribution of Fracture Energy

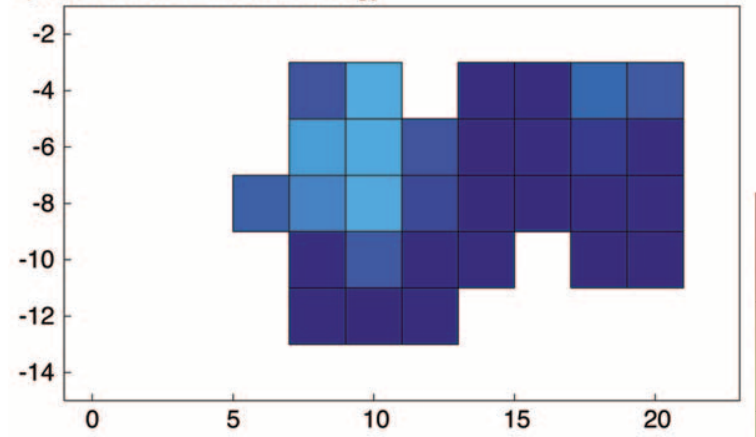

b) Distribution of Near-source Energy

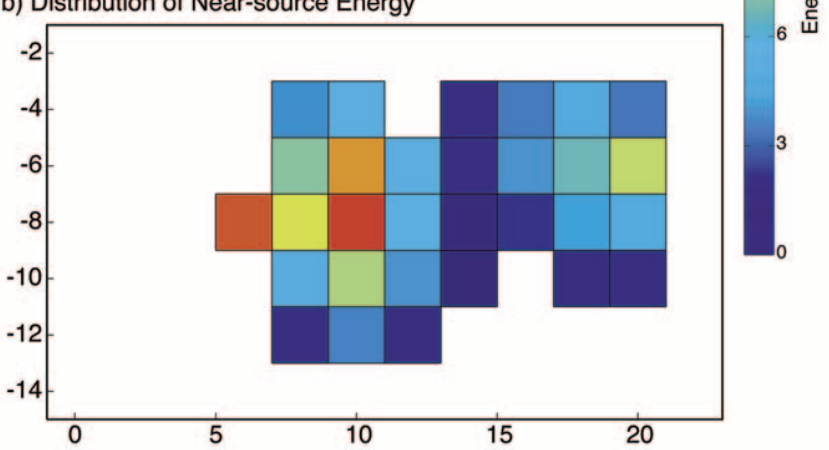

Figure 2. Distribution of the local energies estimated over a major asperity on the fault for the 2002 Tottori, crustal earthquake. (a) Normalized fracture energy $E_{\mathrm{g}_{j}} / A_{j}$. (b) Normalized near-source released energy $E_{\mathrm{q}_{j}}^{g_{j}} / A_{j}$. No reliable data are available on blank subfaults. The abscissa and ordinate, scaled in $\mathrm{km}$, are taken along the strike and dip directions of the fault plane. or $D_{\mathrm{c}}<40 \mathrm{~cm}$ are also not included due to poor resolution. In this case, $\Delta \sigma$ ranges between 2.2 and $12.5 \mathrm{MPa}$, and $\Delta \sigma_{\mathrm{e}}$ ranges between 1.2 and $14.7 \mathrm{MPa}$. The results show that $E_{\mathrm{g}_{j}} /$ $A_{j}$ on two asperities (high slip and large stress-drop zones, in Figs. 3 and 4, Mikumo and Yagi, 2003) ranges between 7 and $13 \mathrm{MJ} / \mathrm{m}^{2}$, while $E_{\mathrm{q}_{j}}^{\prime} / A_{j}$ in these zones is between 10 and $18 \mathrm{MJ} / \mathrm{m}^{2}$. The total energies over 100 major subfaults (each with a dimension of $2.5 \mathrm{~km} \times 2.5 \mathrm{~km}$ ) covering these asperities are $E_{\mathrm{g}}=\Sigma E_{\mathrm{g}_{j}}=3.2 \times 10^{9} \mathrm{MJ}, E_{\mathrm{q}}^{\prime}=\Sigma E_{\mathrm{q}_{j}}^{\prime}=$ $3.9 \times 10^{9} \mathrm{MJ}$, and $2 \Delta W=7.1 \times 10^{9} \mathrm{MJ}$. Their ratios are $E_{\mathrm{q}}^{\prime} / 2 \Delta W=0.55, E_{\mathrm{g}} / 2 \Delta W=0.45, E_{\mathrm{q}}^{\prime} / E_{\mathrm{g}}=1.2$, and $E_{\mathrm{q}}^{\prime} / M_{0}$ $=5.9 \times 10^{-5}$. The ratios indicate that the total near-source energy released on the two major asperities on the fault surface is about $55 \%$ of twice the strain energy and 1.2 times the fracture energy. All these estimated energies are listed in Table 1. It should be noted, however, that these energies do not cover the entire fault surface due to their poor resolution outside major asperities.

The above energies for the two earthquakes have been estimated assuming a linear slip-weakening friction law (An-

\section{a) Distribution of Fracture Energy}

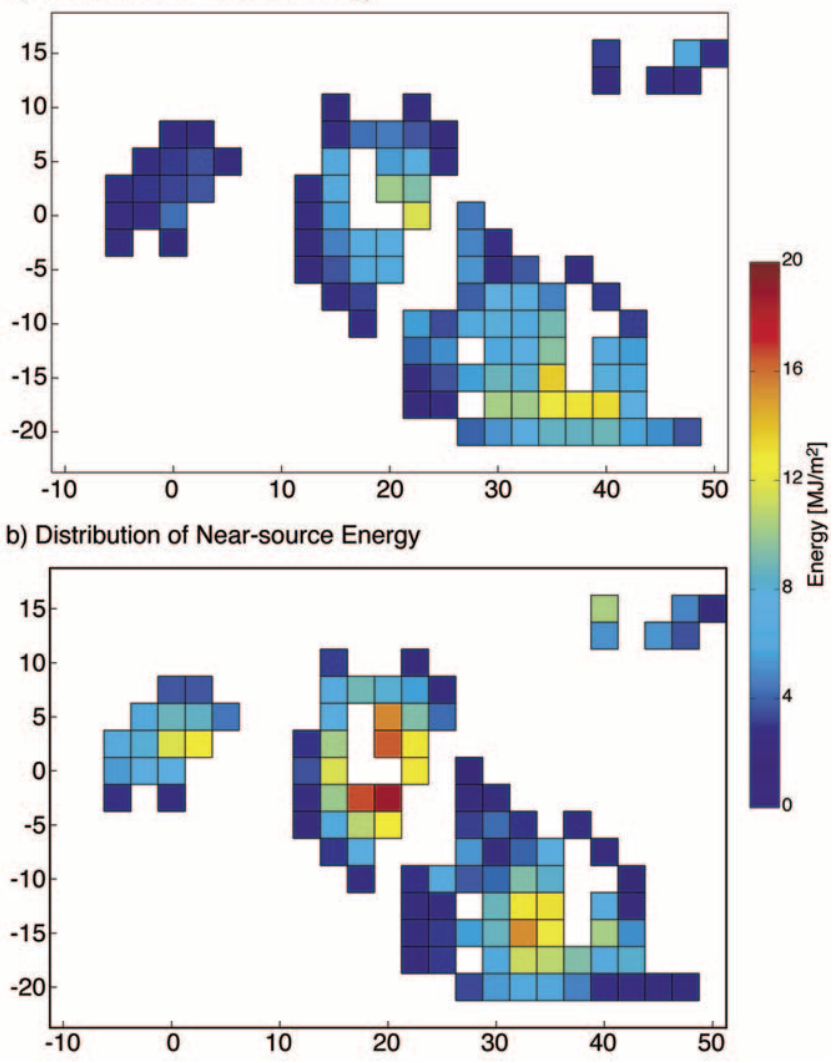

Figure 3. Distribution of the local energies estimated over major asperities on the fault of the 1999 Oaxaca, Mexico, in-slab, normal faulting earthquake. (a) Normalized fracture energy $E_{\mathrm{g}_{j}} / A_{j}$. (b) Normalized near-source released energy $E_{\mathrm{q}_{j}}^{\prime} / A_{j}$. No reliable data are available on blank subfaults. The abscissa and ordinate, scaled in $\mathrm{km}$, are taken along the strike and dip directions of the fault plane. 
Table 1

Estimated Parameters for Two Types of Earthquakes

\begin{tabular}{lcc}
\hline & 2000 Tottori & 1999 Oaxaca \\
\hline Type, depth & crustal, $11 \mathrm{~km}$ & in-slab, $40 \mathrm{~km}$ \\
Dimension & $24 \mathrm{~km} \times 15 \mathrm{~km}$ & $60 \mathrm{~km} \times 40 \mathrm{~km}$ \\
$M_{0}($ dyne $\cdot \mathrm{cm})$ & $1.35 \times 10^{26}$ & $6.65 \times 10^{26}$ \\
$E_{\mathrm{g}_{j}} / A_{j}\left(\mathrm{MJ} / \mathrm{m}^{2}\right)$ & $3-5$ & $7-13$ \\
$E_{\mathrm{q}_{j}}^{\prime} / A_{j}\left(\mathrm{MJ} / \mathrm{m}^{2}\right)$ & $8-12$ & $10-18$ \\
$E_{\mathrm{g}}\left(10^{8} \mathrm{MJ}\right)$ & 2.5 & 32 \\
$E_{\mathrm{q}}^{\prime}\left(10^{8} \mathrm{MJ}\right)$ & 5.9 & 39 \\
$E_{\mathrm{q}}^{\prime} / E_{\mathrm{g}}$ & 2.1 & 1.2 \\
$2 \Delta W\left(10^{8} \mathrm{MJ}\right)$ & 8.4 & 71 \\
$E_{\mathrm{q}}^{\prime} / M_{0}\left(10^{-5}\right)$ & 9.0 & 5.9 \\
\hline
\end{tabular}

$M_{0}$, seismic moment; $E_{\mathrm{g}_{j}} / A_{j}$, normalized fracture energy; $\mathrm{E}_{\mathrm{q}_{j}}^{\prime} / \mathrm{A}_{j}$, normalized released energy; $E_{\mathrm{g}}$, fracture energy over major asperities (high slip and stress-drop-zones); $E_{\mathrm{q}}^{\prime}$, near-source energy released over major asperities (high slip and stress drop-zones); $\Delta W$, strain energy change over the major asperities (after Steketee, 1958).

drews, 1976a,b). If different types of nonlinear friction laws are assumed, our estimate of $D_{\mathrm{c}}$ could be somewhat affected, as has been shown by Fukuyama et al. (2003). In these cases, however, the estimate of the strength excess $\Delta \sigma_{\mathrm{e}}$ would also be changed in such a way that the fracture energy tends to be maintained (Guatteri and Spudich, 2000). Since the first term in equation (2) does not depend on the friction law, $E_{\mathrm{q}}^{\prime}$ would not be much affected.

Comparing these energies in the two types of earthquakes, the fracture energy on the major asperities on the fault of the Oaxaca in-slab earthquake is nearly twice that in the Tottori crustal earthquake. This difference might be attributed to somewhat higher strength of the in-slab fault than that of the shallow crustal fault. On the other hand, the near-source energy density released on the major asperities on the fault are almost the same. It should be noted, however, that $E_{\mathrm{q}}^{\prime}$ is significantly larger than $E_{\mathrm{g}}$ in the two earthquake faults. The total fracture energy over the fault and the nearsource energy are much larger in the Oaxaca earthquake than in the Tottori earthquake. This is simply due to the larger fault size $(60 \mathrm{~km} \times 40 \mathrm{~km})$ of the former earthquake compared to the latter $(24 \mathrm{~km} \times 15 \mathrm{~km})$. It is interesting to note that the ratio of the near-source released energy to fracture energy is somewhat larger in the crustal earthquake than in the in-slab earthquake.

\section{Conclusions}

We have estimated the near-source energy released from the fault and its relation to the fracture energy there, based on a new energy balance equation over the fault (Fukuyama, 2005) under a simple slip-weakening model. These energies have been calculated for the 2000 Tottori, Japan, crustal earthquake $\left(M_{\mathrm{w}} 6.6\right)$ and the 1999 Oaxaca, Mexico, in-slab earthquake $\left(M_{\mathrm{w}} 7.5\right)$ from the spatial distribution of slip, dynamic stress drop, and strength excess, with the critical slip-weakening distance, all of which have been obtained from previous kinematic waveform inversion and dynamic rupture modeling. It was found that the near-source energy released from major asperities (high slip and large stressdrop zones) ranges between 8 and $15 \mathrm{MJ} / \mathrm{m}^{2}$, nearly the same order for the two different types of earthquakes, while the fracture energy to break the in-slab fault needed about twice that of the crustal fault. This might be attributed to higher strength of the in-slab fault, leading to a smaller ratio of the near-source released energy to the fracture energy. The nearsource energy released on the major asperities is significantly larger than the fracture energy for the two types of earthquakes analyzed here.

\section{Acknowledgments}

We have greatly benefited from our conversations with Hiroo Kanamori, Raul Madariaga, and Satoshi Ide about the original version of this manuscript. We also thank David D. Oglesby (Associate Editor) and Pascal Favreau for their comments for improving the manuscript. This study was started while the senior author visited the Earthquake Research Institute, University of Tokyo, Japan, in 2003, as part of the Special Project for Earthquake Disaster Mitigation in Urban Areas. He would like to thank Takashi Miyatake for his invitation. This study was also partly supported by the CONACyT (Mexico) Project No. 41209-F, for which the senior author wishes to thank the assistance of Raul Valenzuela.

\section{References}

Abercrombie, R. E., and J. R. Rice (2004). Can observation of earthquake scaling constrain slip weakening? Geophys. J. Int. 162, 406-424.

Andrews, D. J. (1976a). Rupture propagation with finite stress in antiplane strain, J. Geophys. Res. 81, 3575-3582.

Andrews, D. J. (1976b). Rupture velocity of plane strain shear crack, $J$. Geophys. Res. 81, 5670-5687.

Andrews, D. J. (2004). Rupture models with dynamically determined breakdown displacements, Bull. Seism. Soc. Am. 94, 769-775.

Aochi, H., and S. Ide (2004). Numerical study on multi-scaling earthquake rupture, Geophys. Res. Lett. 31, L02606, doi 10.1029/2003GL018708.

Choy, G. L., and J. L. Boatwright (1995). Global patterns of radiated seismic energy and apparent stress, J. Geophys. Res. 100, 18,205-18,228.

Das, S., and K. Aki (1977). A numerical study of two-dimensional spontaneous rupture propagation, Geophys. J. R. Astr. Soc. 50, 643-668.

Favreau, P., and R. Archuleta (2003). Direct energy modeling and application to the 1979 Imperial Valley earthquake, Geophys. Res. Lett. 30, 1198, doi 10.1029/2002GL015968.

Fukuyama, E. (2005). Radiation energy measured at earthquake source, Geophys. Res. Lett. 32, L13308, doi 10.1029/2005GL022968.

Fukuyama, E., T. Mikumo, and K. B. Olsen (2003). Estimation of the critical slip-weakening distance: theoretical background, Bull. Seism. Soc. Am. 93, 1835-1840.

Guatteri, M., and P. Spudich (2000). What can strong-motion data tell us about slip-weakening fault friction laws? Bull. Seism. Soc. Am. 90, 98-116.

Ide, S. (2002). Estimation of radiated energy of finite-source earthquake models, Bull. Seismol. Soc. Am. 92, 2994-3005.

Ide, S., and G. C. Beroza (2001). Does apparent stress vary with earthquake size? Geophys. Res. Lett. 28, 3349-3352.

Ide, S., and M. Takeo (1997). Determination of constitutive relations of fault slip based on seismic wave analysis, J. Geophys. Res. 102, 27,379-27,391.

Kanamori, H., and T. H. Heaton (2000). Microscopic and macroscopic physics of earthquakes, in Geocomplexity and Physics of Earth- 
quakes, J. B. Rundle, D. L. Turcotte, and W. Klein (Editors), American Geophysical Union Monograph 120, 147-163.

Kanamori, H., E. Hauksson, L. K. Hutton, and L. M. Jones (1993). Determination of earthquake energy release and $\mathrm{M}_{\mathrm{L}}$ using TERRAscope, Bull. Seism. Soc. Am. 83, 330-346.

Kostrov, B. V. (1974). Seismic moment and energy of earthquakes and seismic flow of rock, Izv. Earth Phys. 1, 23-40.

Kostrov, B. V., and S. Das (1988). Principles of Earthquake Source Mechanics, Cambridge University Press, New York, 286 pp.

McGarr, A. (1999). On relating apparent stress to the stress causing earthquake fault slip, J. Geophys. Res. 104, 3003-3011.

Mikumo, T., and Y. Yagi (2003). Slip-weakening distance in dynamic rupture of in-slab normal-faulting earthquakes, Geophys. J. Int. 155, 443-455.

Mikumo, T., K. B. Olsen, E. Fukuyama, and Y. Yagi (2003). Stress-breakdown time and slip-weakening distance inferred from slip-velocity functions on earthquake faults, Bull. Seism. Soc. Am. 93, 264-282.

Ohnaka, M. (2003). A constitutive scaling law and a unified comprehension for frictional slip failure, shear fracture of intact rock, and earthquake rupture, J. Geophys. Res. 108, B2, 2080, doi 10.1029/2000JB000123.

Ohnaka, M., and L.-F. Shen (1999). Scaling of the shear rupture process from nucleation to dynamic propagation: implications of geometric irregularity of the rupture surface, J. Geophys. Res. 104, 817-844.

Okubo, P. G., and J. H. Dieterich (1984). Effects of physical fault properties on frictional instabilities produced on simulated faults, J. Geophys. Res. 89, 5817-5827.

Piatanesi, A., E. Tinti, M. Cocco, and E. Fukuyama (2004). The dependence of traction evolution on the earthquake source time function adopted in kinematic rupture models, Geophys. Res. Lett. 31, L04609, doi 10.1029/2003GRLL019225.

Power, W. L., T. E. Tullis, S. R. Brown, G. N. Boitnott, and C. H. Scholz (1987). Roughness of natural fault surfaces, Geophys. Res. Lett. 14, 29-32.
Scholz, C. H., and C. A. Aviles (1986). The geometry of faults and faulting, in Earthquake Source Mechanics, S. Das, J. Boatwright, and C. H. Scholz (Editors), American Geophysical Union Monograph 37, 147 155 .

Singh, S. K., and M. Ordaz (1994). Seismic energy release in Mexican subduction zone earthquakes, Bull. Seism. Soc. Am. 84, 1533-1550.

Spudich, P., and M. Guatteri (2004). The effect of bandwidth limitations on the inference of earthquake slip-weakening distance from seismograms, Bull. Seism. Soc. Am. 94, 2028-2036.

Steketee, J. A. (1958). Some geophysical applications of the elasticity theory of dislocations, Can. J. Phys. 36, 1168-1197.

Tinti, E., E. Fukuyama, A. Piatanesi, and M. Cocco (2005). A kinematic source-time function compatible with earthquake dynamics, Bull. Seism. Soc. Am. 95, 1211-1223.

Yasuda, T., Y. Yagi, T. Mikumo, and T. Miyatake (2005). A comparison between $D_{c}{ }^{\prime}$-values obtained from a dynamic rupture model and waveform inversion, Geophys. Res. Lett. 32, L14316, doi 10.1029/ 2005GRL023114.

Instituto de Geofisica

Universidad Nacional Autonoma de Mexico

Ciudad Universitaria

Mexico 04510 D.F., Mexico

(T.M.)

National Research Institute for Earth Sciences and Disaster Prevention Tsukuba, Ibaraki 305-0006, Japan

(E.F.)

Manuscript received 10 June 2005. 